\title{
P-0778- The Psychosocial Impact of Type 1 Diabetes On Children 2-8 Years Old in Australia
}

\author{
Hanan Sukkar, D.Ed. Holmesglen Institute
}

\begin{abstract}
Introduction
In Australia, around $95 \%$ of the diabetes found in children is known to be type 1 diabetes (T1D). T1D is one of the most common chronic diseases in children, occurring more frequently than cancer, cystic fibrosis, multiple sclerosis and muscular dystrophy (JDRF, 2017). Diagnosis of T1D in children who are six years of age and younger is growing, and the implications for this cohort of children poses unique challenges regarding the effective management, responsibilities and understanding of the disease by parents, allied health practitioners, preschool and school teachers and peers (Pierce, Kozikowski, Lee \& wysocki, 2017).
\end{abstract}

\section{Children with Diabetes in Preschool \& School \\ Settings}

Whilst inclusive and holistic practices stipulate that all children with diabetes should be given the opportunity to participate in and enjoy all preschool and school activities, free from any related stigma, research reports that one in three children with diabetes exhibit a level of psychosocial distress including: anxiety, depression, and eating disorders (Diabetes Miles Youth Study, 2014; Pierce et al., 2017). Given that diabetes management has the potential to effect learning, academic progression and school outcomes, preschool and school settings should provide an exceptional level of support for children battling with diabetes.

In Australia, children spend $40-50 \%$ of their waking hours in preschools and schools. And for children with T1D that participate in preschool and school settings, they have the right to receive quality support and care from the preschool and school personnel (ISPAD \& IDF, 2011). Teachers should have the ability to demonstrate a level of knowledge, understanding and confidence that enables children with diabetes to feel safe and secure in the learning environment (Diabetes Australia, 2017).

"Mastering Diabetes in preschools and schools" is a publication that has been recently developed by Diabetes Australia and the National Diabetes Service Scheme (2017) to ensure that quality care is provided for children with T1D attending preschools and schools. The publication outlines the importance of up-skilling teaching personnel, and developing a family-centred approach to support children's psychosocial well-being and education. In Australia, educational enrolment and transition policies and disability discrimination legislation acknowledge and promote the involvement of parents in educational decision-making and educational transitions (Australian Government, 2005).

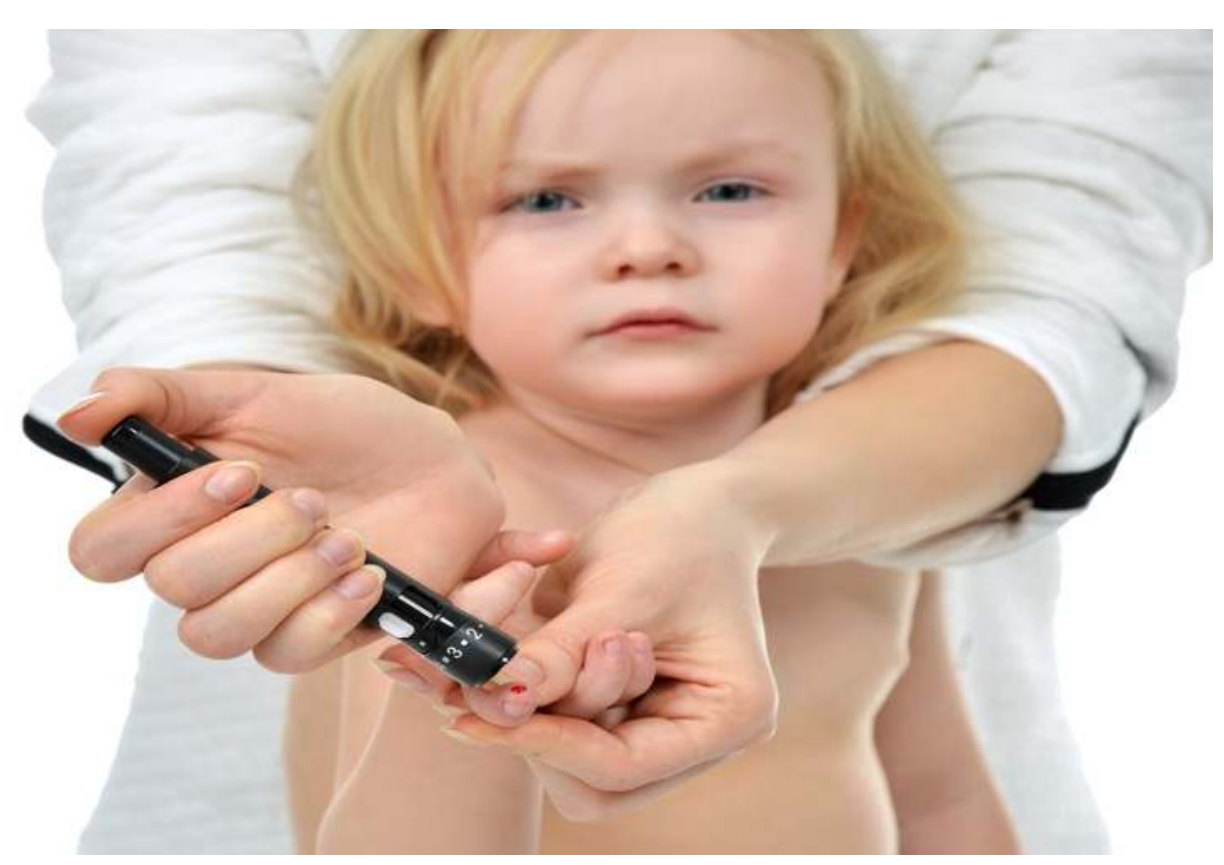

However, the question to be asked today should draw attention on, how can teaching personnel engage, most effectively, with families facing complex challenges, such as, raising a child with $T 1 D ?$

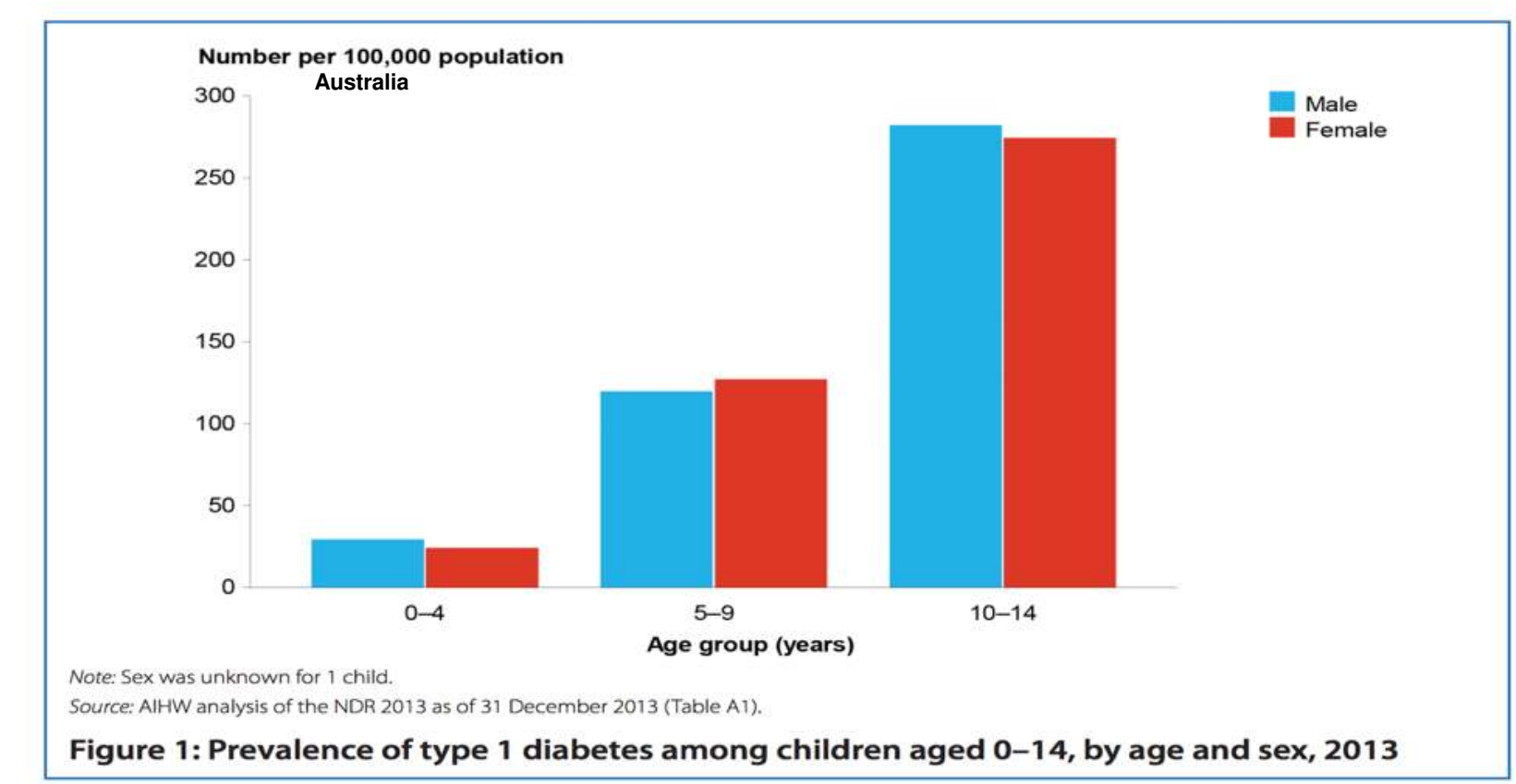

\section{Conclusion}

Research highlights that to develop effective and successful parent-professional partnerships, relationships should be based on the assumption that parents, teaching personnel, and allied health practitioners share a common focus; namely, the parent's child (Sukkar, 2017). They should also have a clear understanding of child development and cognition to ensure that children develop adequate self-care acquisition. To be more specific, in order to support a child's psychosocial and emotional well-being, the focus of the partnership should be on raising the parent-teacher awareness and understanding of children's needs and rights to a quality of life. Teachers who are trained to support children with T1D could improve their academic potential and maximise their cognitive ability (Northam, 2010). On the other hand, parents with high self-efficacy, particularly related to T1D, could influence their child's ability to cope with their unique demands and daily experiences (Pierce et al., 2017).

\section{References}

1. Diabetes Miles Youth Study. (2014). 2014 Survey Report. Retrieved from: https://static.diabetesaustralia.com.au/s/fileassets/diabetesaustralia/c2274d36-ebec-432a-8be5-7c8917db43c1.pdf

2. ISPAD \& IDF. (2011). Global IDF/ISPAD Guideline for Diabetes in Childhood and Adolescence. Retrieved from: http://web.ispad.org/sites/default/files/resources/files/idf-ispad diabetes in childhood and adolescence guidelines $20110 . p d f$

3. Northam, E., Lin, A., Finch, S., Werther, G. A. \& Cameron, F. J. (2010). Psychosocial Well-Being and Functional Outcomes in Youth with Type 1 Diabetes 12 years After Disease Onset. Diabetes Care, 33(7):1430-1437.

4. Pierce, J. S, Kozikowski, C., Lee, M. J. \& Wysocki, T. (2017). Type 1 Diabetes in Very Young Children: A Model of Parent and Child Influences on Management and Outcomes. Pediatric Diabetes, (18), 17-25.

5. Sukkar, H. (2017). Working with Families to Develop Parent-Professional Relationships: Implications for Professional Preparation. In H. Sukkar., C. J. Dunst,\& J. Kikby. (Eds), Early Childhood Intervention: Working with Families of Young Children with Special Needs (pp. 110125). New York: Routledge. 